\title{
Clasificación y análisis espacial de cúpulas y oquedades en los estudios sobre arte rupestre de importancia arqueológica en los Andes orientales de Colombia
}

\author{
Classification and spatial analysis of domes and cavities in rock art \\ studies of archaeological significance in the Eastern Andes of Colombia \\ Laura López Estupiñán* \\ Universidad Pedagógica y Tecnológica de Colombia, Grupo de Investigación Asociación Región
}

\begin{abstract}
$\overline{\text { RESUMEN }}$
Dada la alta presencia de cúpulas en diversos departamentos de Colombia, en este artículo se propone un ejercicio de clasificación, registro y reconocimiento de estas como bienes arqueológicos. Para ello, se diferencia entre cúpulas y oquedades, y se profundiza en los usos culturales documentados hasta el momento en los estudios de arte rupestre; además, se plantea que las cúpulas son insumos de análisis espaciales. Desde una revisión cartográfica y un reconocimiento territorial y arqueológico, la investigación concluye que los soportes rocosos con más de ocho cúpulas se encuentran en valles de ríos e indican relaciones con los cuerpos lacustres, lo que confirma su posible uso como maquetas hídricas.
\end{abstract}

Palabras claves: cúpulas, oquedades, arte rupestre, maquetas hídricas.
DOI: $10.22380 / 2539472 X .1808$

\section{ABSTRACT}

The high presence of domes in various departments of Colombia led to propose a classification, registration and recognition of domes as archaeological assets. To do this, the article differentiates between domes and cavities, delving into the cultural uses documented so far in rock art studies and proposing domes as an input for spatial analysis. From a cartographic review, a territorial and archaeological reconnaissance, it is found that the rocky supports with more than eight domes are found in river valleys and indicate relationships with lake bodies, confirming their possible use as hydric models.

Keywords: domes, cavities, rock art, water models. 


\section{Introducción a las cúpulas en los Andes orientales}

La documentación de arte rupestre en la cordillera de los Andes refiere a cinco tipos de manifestaciones: pictografías, petroglifos, pictograbados, cúpulas y geoglifos. Estas difieren principalmente en la técnica y el uso de materias primas para su elaboración. Las pictografías tienen que ver con la utilización de pigmentos sobre una superficie rocosa y los petroglifos refieren a grabados sobre roca; las asociaciones entre una técnica y otra evidencian superposiciones de pictografías sobre petroglifos llamados pictograbados. Los geoglifos corresponden a dibujos y representaciones hechos sobre la superficie de la tierra. Es menor el estudio de las cúpulas, es decir, la talla de agujeros en soportes rocosos, y aun menor el de superposiciones de pictografías y petroglifos sobre cúpulas y oquedades.

Aunque la Fundación Desierto de Atacama (2016) solo reconoce los petroglifos, pictografías, pictograbados y geoglifos como elementos del arte rupestre, es común encontrar estudios que definen las cúpulas como petroglifos hemisféricos (Gutiérrez, González y Artiles 2014), depresiones (Ponzio 2018) u hoyos que evidencian trabajo humano, sea por la técnica de elaboración (percusión o abrasión) o por la adecuación de oquedades naturales que son pulidas en sus paredes, a las cuales se les da terminaciones planas, cóncavas o convexas. "Se trata de oquedades grabadas mediante técnicas diferentes (picado, raspado, pulido) en la superficie rocosa - paredones verticales, soportes horizontales o inclinadosen diferentes dimensiones y combinadas o no a otros registros" (Ponzio 2018, 79).

La manipulación humana evidenciada en las cúpulas, así como la distribución de cúpulas en el soporte rocoso y su entorno, permiten plantear una posible aproximación a la representación de algo mediante una o varias marcas (cúpulas) en un paisaje. Por ende, las cúpulas hacen parte del arte rupestre, no solo por su valor estético reflejado en diversidad de formas y tamaños, asociaciones con otras manifestaciones rupestres (pictografías o petroglifos) y varias técnicas de elaboración, sino por su intención de recrear y comunicar algo.

La diferencia en los tamaños, las técnicas de elaboración y los lugares de aparición hicieron posible diferenciar las cúpulas de las oquedades. Las primeras aparecen generalmente en grupos sobre una misma superficie de la roca, en espacios públicos donde delimitan áreas o son parte de plazas y caminos. Aunque se ha estudiado y documentado menos que los petroglifos y las pictografías (Bednarik 2008; Ponzio 2018), su documentación arqueológica es común en el área andina meridional, en países como Argentina, Chile, Bolivia y Perú (Ponzio 2018). 
Para el caso peruano, las cúpulas de gran tamaño que están en los sitios arqueológicos de la sierra hacen parte de estructuras arquitectónicas monumentales de Chavín de Huantar y Machu Picchu y se encuentran a las afueras de Kuelap (provincia de Luya) y Anta Ragá (provincia de Raimondi): “Las cúpulas aparecen estrechamente ligadas a las manifestaciones arquitecturales del fin del Formativo, pero también en sitios sin arquitectura, al lado de otras manifestaciones rupestres (petroglifos, estelas)” (Guffroy 2011, 81).

Algunos arqueólogos relacionan las cúpulas con la observación de astros (Milla 2006), cultos al agua (Aschero 2007) y cultos agrícolas (Menghin 1958; Schobinger 1969). La diversidad de tamaños ha permitido atribuir usos relacionados con ritos de fertilidad (Querejazu 1998), funciones de molienda, prácticas de sacrificios y/o adivinación (Guffroy 1999; 2011). Methfessel y Methfessel (1998) documentan tres tipos de cúpulas definidas por forma de elaboración y uso: las auténticas, que tienen el borde circular bien definido (como una taza o plato); las utilitarias, que han sido usadas como batanes o moledores; y con anillos, "rodeadas de uno a más anillos acanalados, alrededor de cúpulas o huecos de origen natural” (36).

A pesar de la evidente intervención humana en la elaboración de las cúpulas, su estudio es menor en Colombia. Estas se encuentran en cercanías de fuentes de agua, ríos o quebradas y son parte de sitios con arte rupestre en los departamentos de Boyacá, Cundinamarca, Guainía (Ortiz y Pradilla 2000) y Putumayo (Flórez 2008), así como de lugares arqueológicos monumentales de San Agustín (Huila) y Tierradentro (Cauca). Algunas se asocian a canales y petroglifos en San Agustín y la provincia del Tequendama (Cundinamarca); también están en sitios con pictografías en Facatativá (Cundinamarca), Cómbita, Gámeza, Monguí, Motavita, Toca, Tunja y Turmequé (Boyacá).

\section{Acercamiento metodológico a las cúpulas en Boyacá, Colombia}

Bednarik (2008) describe tres características de las cúpulas: deben haber sido elaboradas por mano humana, mediante numerosos golpes de percusión y haberse hecho deliberadamente con funciones de carácter no utilitario o simbólico. Sin embargo, en Boyacá se han documentado usos rituales y domésticos en soportes rocosos con menos de cinco cúpulas (López 2011). Boyacá es un departamento ubicado en el centro de Colombia y sobre los Andes orientales; histó- 
ricamente ha sido reconocido como territorio chibcha y arqueológicamente se conocen dataciones de 8000 a.C. asociadas a recolectores cazadores. En cuanto a periodos culturales de sociedades cerámicas en el altiplano de Cundinamarca y Boyacá, se reconocen tres periodos: el Herrera (400 a.C.-1000 d.C.), el Muisca (1000-1600 d.C.) y el Colonial o Moderno (1600-1820 d.C.) (Langebaek 2019).

Para el caso boyacense, se observa una relación entre sitios con arte rupestre, fuentes de agua y caminos prehispánicos documentados en fichas de registro. Actualmente las cúpulas y oquedades son denominadas moyas por los pobladores de la región, lo que es un indicador de la importancia y permanencia cultural. Se encuentran superposiciones de pictografías y petroglifos sobre oquedades que evidencian un uso cultural por parte de las poblaciones prehispánicas de la región. Para su estudio se requirió una documentación en cuatro fases: revisión documental, prospección regional, registro sistemático y análisis espacial comparativo. A partir de lo anterior se pudieron clasificar las cúpulas, así como comprender sus usos y funciones actuales.

La revisión documental priorizó la documentación y el estudio del arte rupestre en Colombia, las prospecciones arqueológicas realizadas en los Andes orientales y el archivo del Museo Arqueológico de Tunja de la Universidad Pedagógica y Tecnológica de Colombia (UPTC). Terminada la revisión, se llevó a cabo una prospección regional para identificar, documentar y registrar los soportes rocosos con cúpulas y oquedades presentes en el departamento de Boyacá (figura 1). Una vez identificados los sitios, se profundizó el estudio en las provincias del Tundama, Sugamuxi, Centro, Márquez y Valderrama. Se recurrió a diversas épocas del año para realizar trabajos investigativos independientes (2011-2015), prácticas académicas con los estudiantes de la UPTC (2016-2019) y el acompañamiento de varios trabajos de grado. Estos ejercicios no requirieron de intervenciones al suelo, sino que fueron fundamentalmente prospecciones superficiales que permitieron realizar un reconocimiento de la información contenida en cada soporte rocoso.

En un primer ejercicio se vincularon aspectos técnicos de las fichas de registro y documentación elaboradas por el Grupo de Arqueología del Instituto Colombiano de Antropología e Historia (ICANH) y el Grupo de Investigación en Pintura Rupestre Indígena (Gipri). Sin embargo, con el avance de la investigación se hizo necesario diseñar una ficha de registro especial para cúpulas, puesto que así lo requerían las características en los números de cúpulas, las técnicas de elaboración de bases y paredes, y el detalle y la forma de los soportes rocosos donde se encuentran las cúpulas (tabla 1). 
Figura 1. Presencia de cúpulas en los municipios de Boyacá al 2020, Andes orientales, Colombia

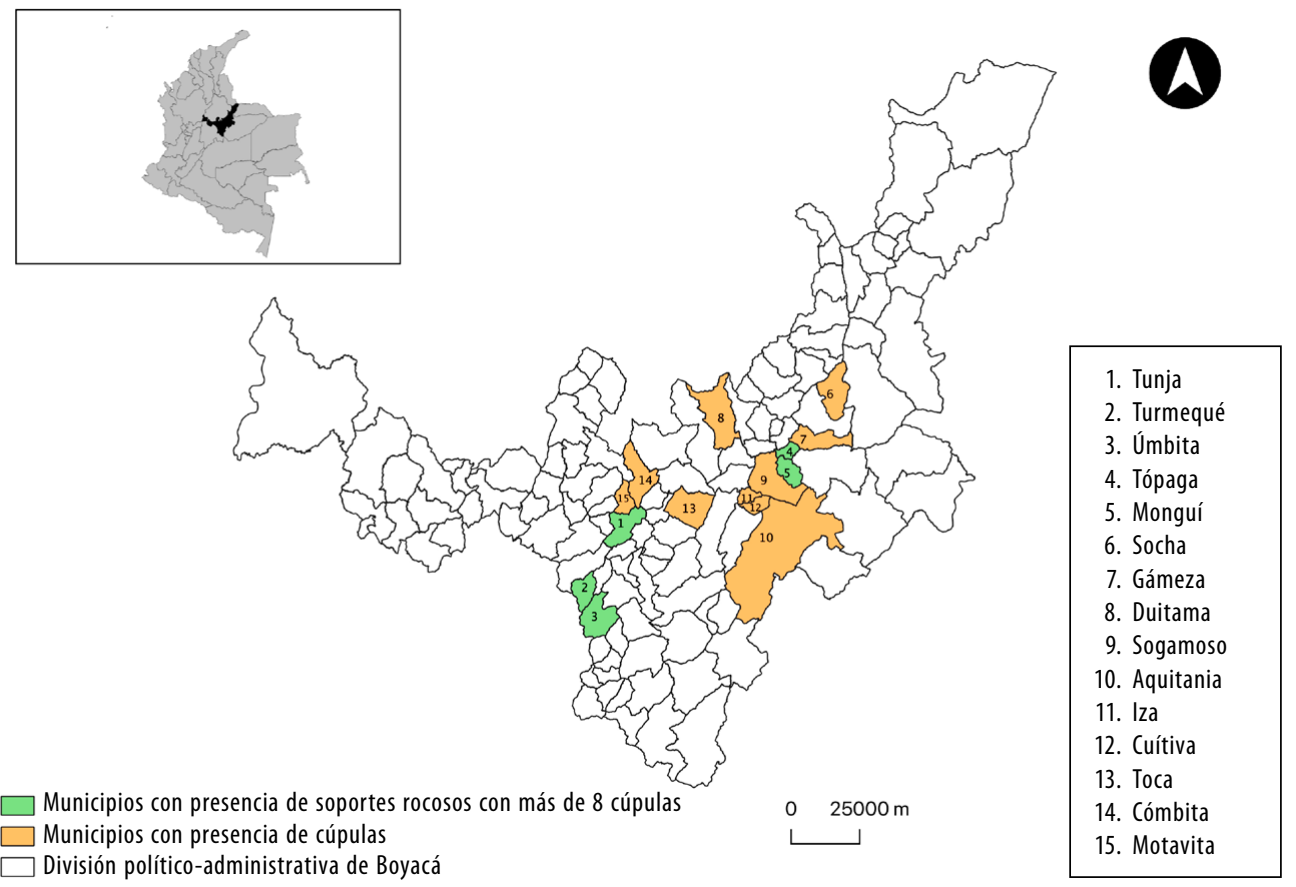

Fuente: elaboración propia con base en cartografía del Sistema de Información Geográfica para la Planeación y el Ordenamiento Territorial (SIG-OT). 
Tabla 1. Ficha para el registro de cúpulas.

\section{Ficha registro de cúpulas. Bienes inmuebles del patrimonio arqueológico}

\section{Identificación del reporte}

\begin{tabular}{l|l|l} 
Fecha (día/mes/año) & Número de radicado \\
\hline Tipo de reporte $\quad$ Hallazgo fortuito $\bigcirc$ Investigación $\bigcirc$ & Número de licencia \\
\hline Nombre del proyecto &
\end{tabular}

Departamento

Municipio

Vereda

¿Cómo llegar?

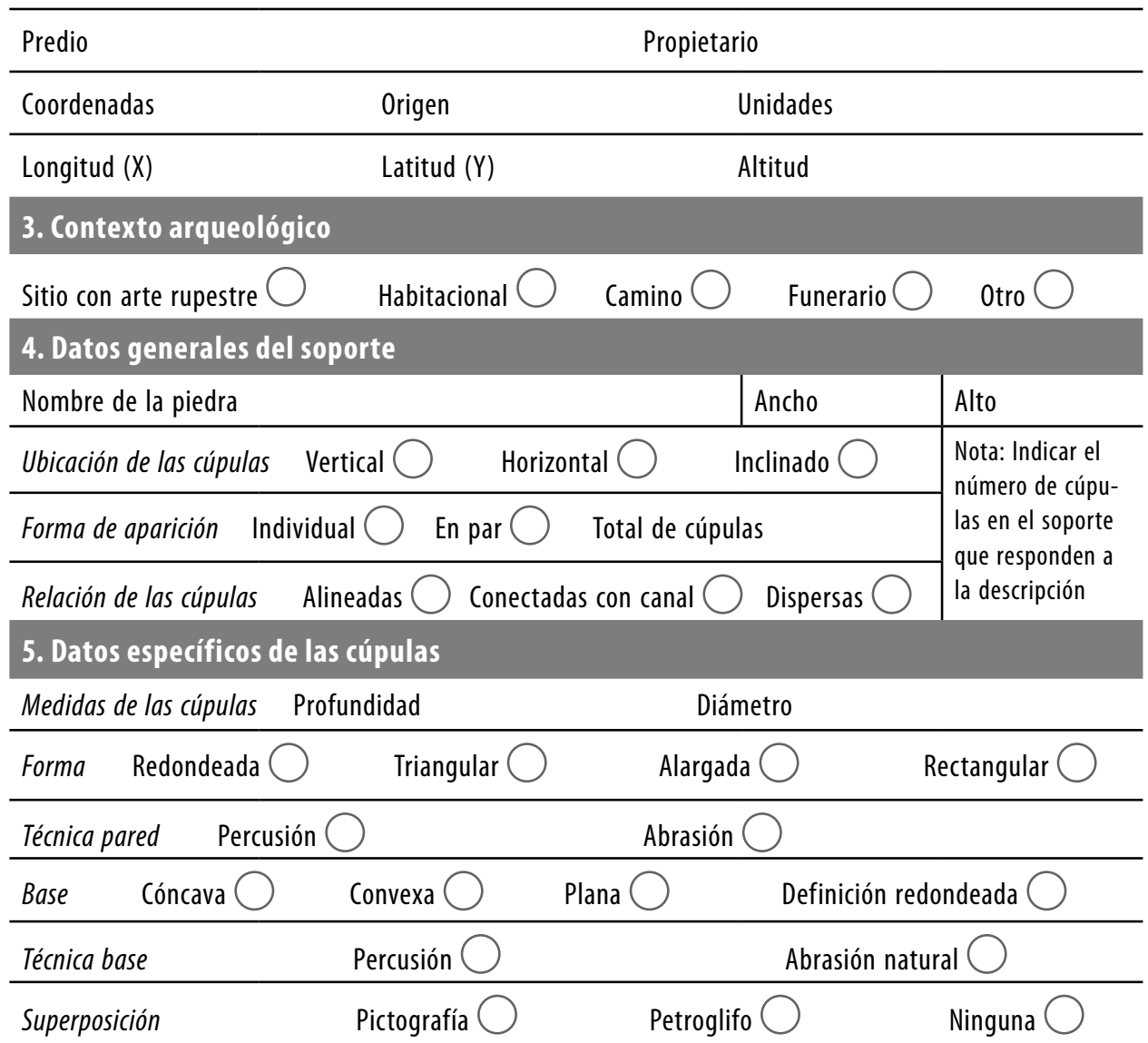




\section{Información de quién reporta}

Apellidos

Nombres

Documento de identidad

Dirección

Municipio

Departamento

Celular Correo electrónico

Ocupación

Institución

Fuente: elaboración propia.

El registro de cúpulas en la ficha estuvo acompañado de un registro fotográfico que permitió realizar un análisis de sus características y patrones, con lo cual se encontró una diferencia en el interior del grupo de moyas, dada por las técnicas de elaboración (cúpulas) y la apropiación cultural (oquedades). Cada una de las fichas fue alimentando una base de datos en la que se registraron 34 rocas en 22 sitios con arte rupestre de 15 municipios de Boyacá, con un total de 123 cúpulas, de las que solo 30 aparecen de forma individual en un mismo soporte (tabla 2). 


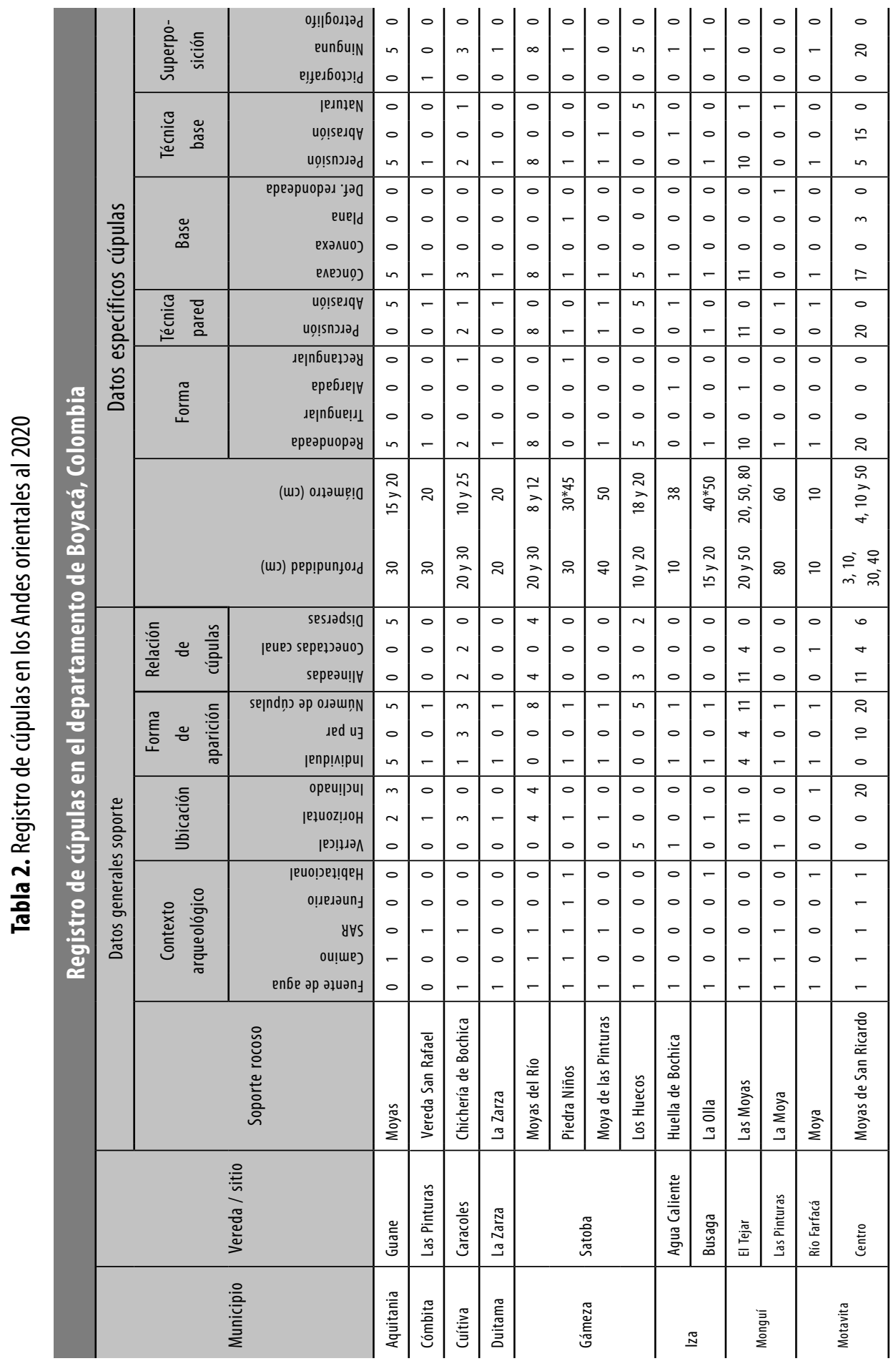




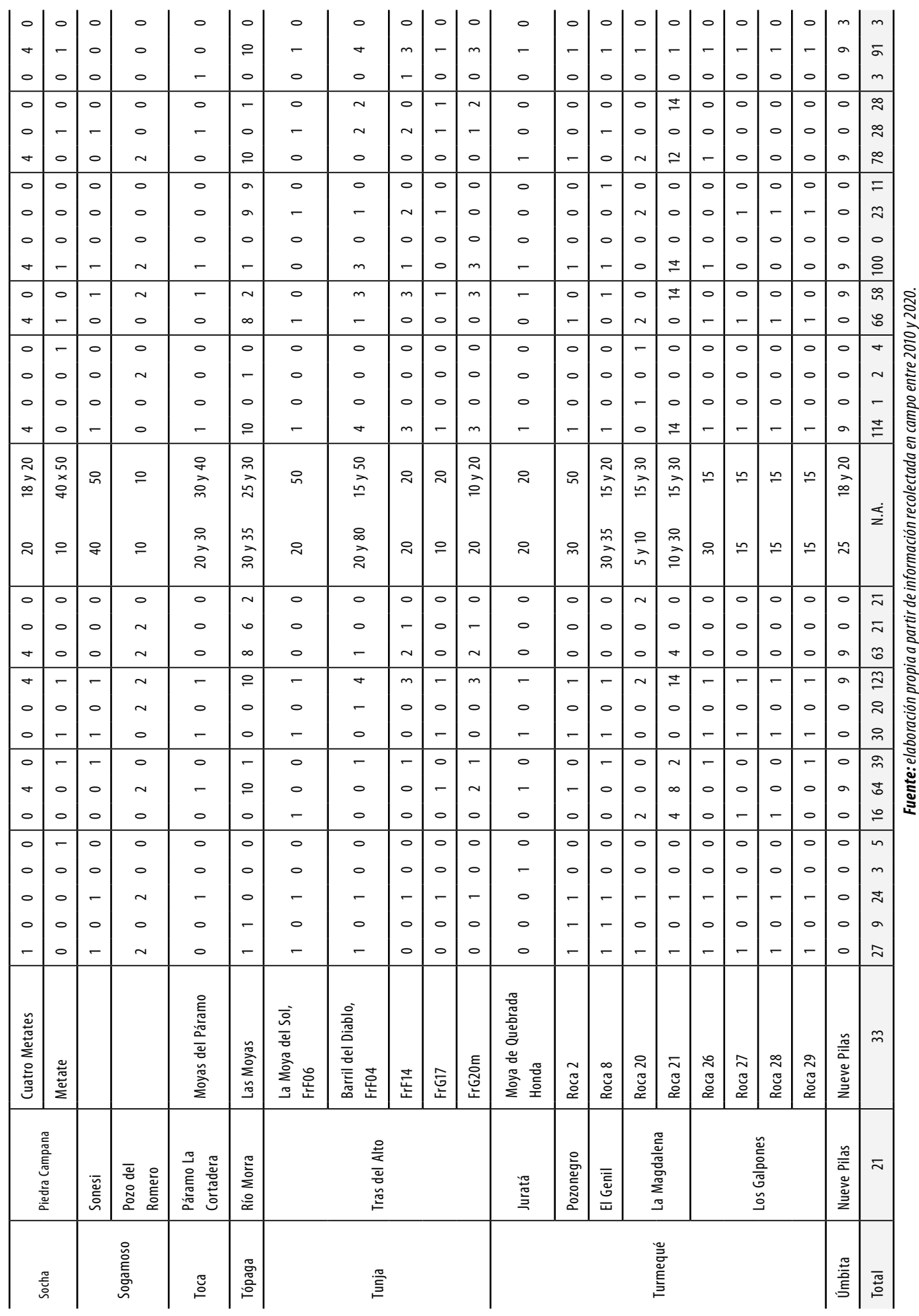


Es necesario aclarar la existencia de cientos de rocas con oquedades en los sitios arqueológicos que, al no tener las evidencias de manipulación humana para su elaboración ni en pared ni en base, no fueron registradas como cúpulas, lo que reduce el número de aparición en los sitios prospectados. Muy posiblemente el número de cúpulas aumente con una limpieza de los soportes rocosos y la intervención de estos, para lo cual se sugiere realizar trabajos de excavación que permitan recuperar la mayor cantidad de información de las rocas y ayuden en la comprensión de los sitios.

En quince municipios se encontraron patrones de elaboración de las cúpulas, así como diferencias en las formas, terminados de bases y paredes. Con base en los hallazgos se generó una clasificación tipológica, determinada por las técnicas de elaboración de la pared y la base (abrasión o percusión), la forma de la cúpula (redondeada, alargada o cuadrangular), el terminado de la base (cóncava, convexa, plana o con definición redondeada) y la superposición (pictografías, petroglifos o ninguna) (figura 2).

Figura 2. Tipos de cúpulas documentadas en los Andes orientales hasta el 2020

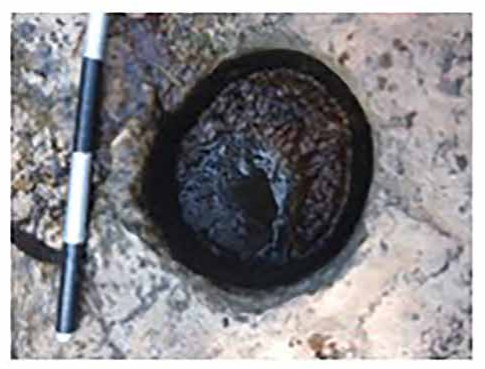

\author{
Cúpula redondeada, \\ base plana \\ definición redondeada \\ $9 \%$
}

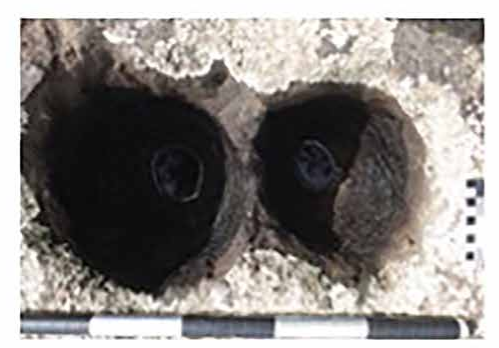

Cúpula redondeada, base cóncava $81 \%$

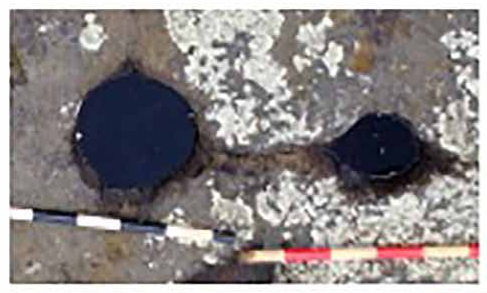

Cúpulas redondeadas concectadas por canal $17 \%$ 
Tras definir las características e identificar algunos patrones en soportes rocosos con cúpulas, se inició un análisis espacial para contrastar tales soportes con la información arqueológica reportada en investigaciones realizadas en los sitios cercanos. Se encontró que la mayor parte de soportes rocosos con más de 8 cúpulas están en un perímetro máximo de $2 \mathrm{~km}$ de los sitios con arte rupestre, como si demarcaran sectores y corredores de pictografías o petroglifos; mientras que los soportes rocosos con menos de 7 cúpulas hacen parte de los corredores de arte rupestre.

Los sitios con arte rupestre del Pedregal (Sogamoso), el Farfacá (Tunja y Motavita), Socha y Turmequé tienen en común la existencia de pictografías de color rojo y la poca presencia o ausencia de petroglifos. Los soportes rocosos están dispersos en la ribera de las quebradas y cuentan con presencia de cúpulas al inicio o fin del sitio (generalmente la parte más estrecha del valle), como si los soportes rocosos con cúpulas delimitaran el sitio con arte rupestre. En el Farfacá se encuentran Las Moyas de San Ricardo, en Turmequé están Las Moyas, en Socha está la Piedra de los Metates y en el Pedregal (Sogamoso) están las cúpulas del Pozo del Romero. Es de recordar que, para los muiscas, las fuentes de agua, cañadas, quebradas y lugares donde se asocian la piedra y el agua eran sitios de culto y ritual, tal como lo exponen Correa (2004), Rozo (1997), entre otros autores.

La forma de la cúpula se asemeja a un contenedor de agua. Todas las cúpulas tienen base cóncava (100) o plana (23); de los 33 soportes rocosos con cúpulas documentados, 27 están relacionados con fuentes de agua, principalmente quebradas a menos de 100 metros. Esta relación con el agua lleva a que no se descarte la hipótesis de los soportes rocosos como maquetas hídricas, y que se proponga un análisis espacial regional que vincule los cuerpos de agua existentes en las cuencas de los ríos Chicamocha, Garagoa, Cravo Sur y el lago de Tota; para ello, se recurrió a la cartografía del Instituto Geográfico Agustín Codazzi (IGAC) y se contrastó con los hallazgos arqueológicos y la ubicación de los soportes rocosos con cúpulas.

\section{Propuesta clasificatoria de moyas para Colombia}

Las primeras documentaciones de moyas en Boyacá se realizaron en los años ochenta, cuando Castillo (1984) y Lleras (1986) registraron fotográficamente dos piedras de gran soporte en límites de Tunja y Motavita (Moyas de San Ricardo) y Úmbita (Nueve Pilas). Sin embargo, no existe un documento que refiera espe- 
cifícamente a las cúpulas, ya que pocas veces se incluyen dentro de los registros arqueológicos y catálogos de rocas. Este vacío motivó el estudio de las cúpulas como eje particular de la investigación en arte rupestre desde 2010, y ha venido ampliando el interés en estudios espaciales para comprender sus posibles usos y funciones en épocas prehispánicas.

Para nuestro caso, se recurrió a un primer inventario y clasificación de las cúpulas en 23 sitios arqueológicos de 15 municipios de Boyacá. Como resultado se obtuvo una base de datos a partir de la cual se hizo una lectura general del soporte y de las cúpulas. Allí se encontraron patrones en la técnica de elaboración (78 por percusión en la base), en la forma (114 redondeadas) y en la base (100 cóncavas). El registro de cúpulas para Boyacá fue complementado con una revisión de las investigaciones arqueológicas de los sitios, los usos culturales documentados en los estudios de arte rupestre en los Andes y trabajos etnográficos relacionados con el uso de la piedra en Colombia. Lo anterior permitió identificar otras cúpulas en cercanías de sitios arqueológicos, así como diferenciar entre oquedades, petroglifos cupulares y cúpulas (figura 3 ).

Figura 3. Oquedades, petroglifos cupulares y cúpulas
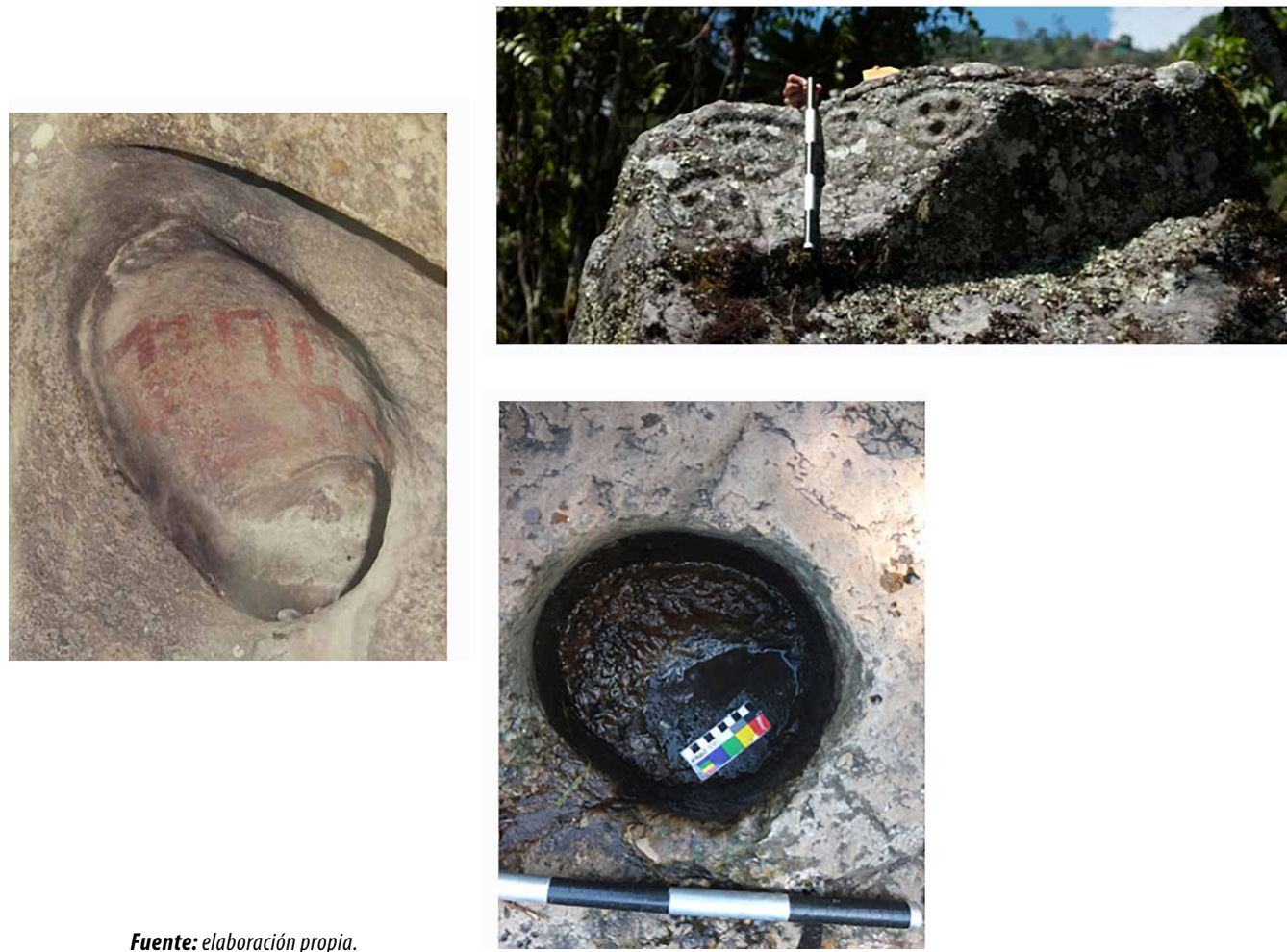

Fuente: elaboración propia. 


\section{Oquedades}

Las oquedades corresponden a orificios naturales que fueron adaptados culturalmente por diversos grupos humanos. Oscilan entre los 30 y $80 \mathrm{~cm}$ de diámetro en riberas de los ríos Guayabero y Guainía (Ortiz y Pradilla 2000); La Vega (Pradilla y Villate 2010), Nerita (Benavides 2020), Sasa, Morra (López 2011) y Monguí en Boyacá; el río Cascajo en Sibundoy (Flórez 2008); el río Orinoco y la quebrada del Lavapatas de San Agustín. En las paredes de este tipo de oquedades hay evidencias de manipulación humana, ya sea por abrasión o por la superposición de pictografías en bases y paredes.

Las superposiciones de pictografías en moyas han sido documentadas en Motavita (Pradilla y Villate 2010), el cañón del río Chicamocha (León, Barón y Giedelmann 2018), Soacha (Municipio de Soacha, Idecut, Fundación Erigaie s.f.), Une (Botiva y Martínez 2004) y Toca. Aunque son más escasas, dan cuenta del uso cultural prehispánico y la importancia de marcarlas con algún pigmento. También se han encontrado oquedades de gran tamaño en Facatativá (Rodríguez 2015) y el río Guainía (Ortiz y Pradilla 2000), las cuales tienen un diámetro mayor a los $80 \mathrm{~cm}$. Para el caso del Guainía, las oquedades aún cuentan con usos rituales entre las comunidades indígenas saliva y piapoco, mientras las oquedades de las Piedras del Tunjo en Facatativá (Rodríguez 2015) y la Chichería de Bochica en Cuítiva (López 2019) se caracterizan por su uso como contenedores de chicha, de igual manera que se documenta en Perú (en Kenko) y Bolivia.

Las oquedades funcionan como contenedores de agua. Por los trabajos etnográficos, sabemos de la elaboración de caldo de piedra en oquedades de Oaxaca (México), un uso similar al registrado en los años ochenta en Boyacá cuando eran utilizadas como contenedores de alimentos en la provincia de Sugamuxi (Colombia); de ahí que se les reconozca con el nombre de moyas, con el que también se denominan las ollas. Dichos usos no se descartan en épocas prehispánicas: rocas con huellas de termofractura en cercanías de cúpulas y estructuras de combustión en sitios arqueológicos de Chile, Argentina, Bolivia y Perú hacen pensar en una probable utilización para hervir el agua que allí se deposita, y no solo en la preparación tradicional de curantos (Rivas y Ocampo 2005), taques y pachamancas. 


\section{Petroglifos cupulares}

Los petroglifos cupulares son cúpulas pequeñas elaboradas por percusión que hacen parte de figuras geométricas (Cundinamarca, Guaviare, Santander, Nariño), zoomorfas (Guaviare), antropomorfas (Boyacá, Cundinamarca), lineales (Cauca, Nariño) y dispersas (Gorgona). Su documentación ha sido más juiciosa en los estudios de arte rupestre. Los hallamos en los municipios de Buenavista, Ciénega, Gámeza, Iza, Pesca, Ramiriquí, Rondón, Tipacoque y Tutazá (departamento de Boyacá).

\section{Cúpulas}

Las cúpulas evidencian manipulación humana en la técnica de elaboración; tienen perfiles y bases totalmente hechos por percusión o abrasión. A la fecha se han encontrado cuatro tipos de cúpulas: redondeadas, triangulares, rectangulares y alargadas. Las cúpulas documentadas en las investigaciones arqueológicas son las rectangulares, elaboradas por percusión, de base plana o cóncava que no supera el metro de largo; son conocidas como batanes, piedras de moler, metates y pilones, y están asociadas a la transformación de alimentos, principalmente granos y vegetales. Se encuentran de forma individual en un mismo soporte, asociadas a sitios habitacionales y rituales.

Benavides (2020) registra una cúpula triangular en Turmequé, con una función posiblemente ritual, debido a su ubicación en el soporte, profundidad y base plana. Aunque su presencia es menor, también se han registrado cúpulas rectangulares de gran tamaño, conocidas como piedras batea en el Putumayo o como pilas y piletas en el interior del país. Este tipo de cúpulas se relaciona con usos rituales para baños de protección de niños en Boyacá (López 2011), usos bautismales en el Valle de Sibundoy (Flórez 2008), y usos domésticos y ganaderos en gran parte del país.

Se han registrado numerosas piedras con cúpulas alargadas elaboradas por percusión que parecen corresponder a canales en Putumayo (Flórez 2008) y Huila. Existen cúpulas alargadas con terminación cóncava que evidencian manipulación humana por abrasión, aunque parecen corresponder a formaciones de origen natural con adaptaciones culturales por diversos grupos humanos. En sus paredes y bases hay huellas de rayados o raspados que, según describe fray Pedro Simón (1981), se hacían para tener un buen parto. 
El tercer grupo de cúpulas corresponde a las redondeadas, que tienen una terminación cóncava o plana; generalmente se encuentran varias en un mismo soporte rocoso de gran tamaño, cerca de fuentes hídricas y caminos. Oscilan entre los 15 y $50 \mathrm{~cm}$ de diámetro, con profundidades mayores a los $10 \mathrm{~cm}$; están cubiertas por tierra o llenas de agua. Al documentar las formas y técnicas de elaboración se identificaron dos tipos: las cónicas cóncavas y las cilíndricas planas.

A la fecha se han registrado cúpulas redondeadas en Aquitania, Cómbita, Duitama, Monguí y Toca. También se han documentado en Cota, Cuítiva (López 2019), Gámeza, Mongua, Tópaga (López 2011), Tunja (Castillo 1984), Motavita (Pradilla y Villate 2010), Mesitas del Colegio (Muñoz 2006), Socha (Fundación Cultural Benítez 2016), San Agustín (Milla 2006), Turmequé (Benavides 2020), Úmbita (Lleras 1986) y el Valle de Sibundoy (Flórez 2009). Dentro del grupo de cúpulas redondeadas encontramos algunas de menor tamaño, las cuales oscilan entre los 5 y $10 \mathrm{~cm}$ de diámetro, con profundidades entre los 3 y $8 \mathrm{~cm}$. Hasta el momento, este tipo de cúpulas hace parte de los mismos soportes rocosos en donde se encuentran las anteriormente descritas.

Aunque no es común hallar canales que permitan la conexión de cúpulas en un mismo soporte, se registraron veintitrés cúpulas conectadas con canal en Boyacá, correspondientes a cuatro piedras (Moyas de San Ricardo, Moyas del río Morra, Moyas de Turmequé y Moyas de Monguí). Las cúpulas están vinculadas con canales naturales, grietas o canales elaborados que descienden y conectan entre sí. Dicha particularidad sucede en rocas de gran tamaño y con más de ocho cúpulas en la superficie.

La intención de hacer canales entre cúpulas y aprovechar las fisuras de la roca probablemente indique un uso distinto al doméstico, de forma similar al sitio Kalatrancani en Bolivia, donde:

las cúpulas en las partes más altas de las rocas, que mantenían el agua (o algún otro líquido elemento), y cuyo rebalse fluía hacía abajo, a lo largo de los conductos, eran utilizadas en ritos que servían para fecundar o fertilizar simbólicamente las tierras circundantes a las rocas que contenían las cúpulas, conductos y grietas naturales por donde bajaba el líquido elemento. (Querejazu 1998, 49)

Las representaciones de fuentes de agua en el arte rupestre han sido documentadas por Aschero (2007), Carrión (2005) y Troncoso (1998) en América del Sur, quienes proponen su función como maquetas hídricas, pues señalan lagunas o pozos en las cúpulas y posibles ríos en los canales. Lo descrito es una interpretación probable para el caso de las cúpulas en Boyacá, más aún si tenemos en 
cuenta que las piedras registradas se localizan en las partes bajas de los valles, en riberas y en cercanías de caminos.

Teniendo en cuenta el planteamiento anterior, se documentaron 5 soportes rocosos con más de 8 cúpulas en Úmbita, Turmequé, Tópaga, Monguí y Tunja (figura 1). A su vez, se realizó un análisis espacial de los soportes rocosos que evidenció un patrón en la distribución de cúpulas y la geolocalización de los soportes; a saber, se encuentran a menos de $20 \mathrm{~km}$ lineales de las lagunas que conforman el ecosistema de alta montaña andino, conocido como páramo, y el número de cúpulas de los soportes a veces coincide o se acerca al número de lagunas de las partes altas.

La cantidad de lagunas en épocas prehispánicas probablemente no corresponde a la actual. Solo en los últimos veinte años hemos visto secarse una buena suma de cuerpos de agua, pero posiblemente la representación de cúpulas como contenedores cóncavos y planos, la diversidad de tamaños en un mismo soporte y la distribución de las cúpulas dentro de este sugieran una lectura más amplia del territorio.

\section{Distribución y análisis espacial de soportes rocosos con cúpulas en Boyacá}

Las 123 cúpulas registradas en Boyacá están por encima de los 2300 ms.n.m., en cercanías de fuentes de agua y sitios con arte rupestre de Cuítiva, Gámeza, Monguí, Motavita, Socha, Sogamoso, Toca, Tópaga, Tunja y Turmequé. Aunque los estudios arqueológicos en los sitios han sido pocos, las prospecciones y estudios de Argüello (2016), Benavides (2020), Castillo (1984), Fajardo (2016), Lleras (1986), López (2011) y Pradilla y Villate (2010) han mostrado una correlación con asentamientos de los periodos Muisca y Herrera.

Solamente 4 rocas de las 33 registradas hasta el momento se relacionan directamente con sitios habitacionales, distribución espacial que confirmaría el posible uso doméstico de las cuatro cúpulas rectangulares de los municipios de Iza, Turmequé, Gámeza y Socha. Más de la mitad de las cúpulas (79) se encuentran en solo 8 soportes rocosos, frente a lo que nos preguntamos: ¿por qué existían soportes rocosos aislados con varias cúpulas en su superficie?, ¿cuáles serían sus usos?, ¿en qué podrían diferenciarse de las cúpulas individuales?

Para responder estos interrogantes, se recurrió a los planteamientos de Marchante (2016), quien se refiere a la necesidad de un análisis de la estación 
rupestre, el entorno y el paisaje, lo cual amplía la mirada más allá del objeto y reconoce la construcción territorial en épocas prehispánicas. Ante la propuesta, se realizó el análisis espacial y la distribución de cúpulas en 4 de los soportes cuyo contexto arqueológico ha sido explorado: Las Moyas de San Ricardo (Tunja), las Moyas del río Morra (Tópaga), el soporte rocoso 20 del sitio con arte rupestre (SAR) La Magdalena (Turmequé) y Las Moyas del Tejar (Monguí). Posterior al análisis del contexto arqueológico, se recurrió a la cartografía hídrica, principalmente de cuencas y lagunas documentadas por el IGAC, en donde se encontraron relaciones en el número de cúpulas y lagunas de las fronteras de las cuencas (figura 4).

Figura 4. Presencia de cúpulas, lagunas y cuencas en los Andes orientales, Boyacá, Colombia

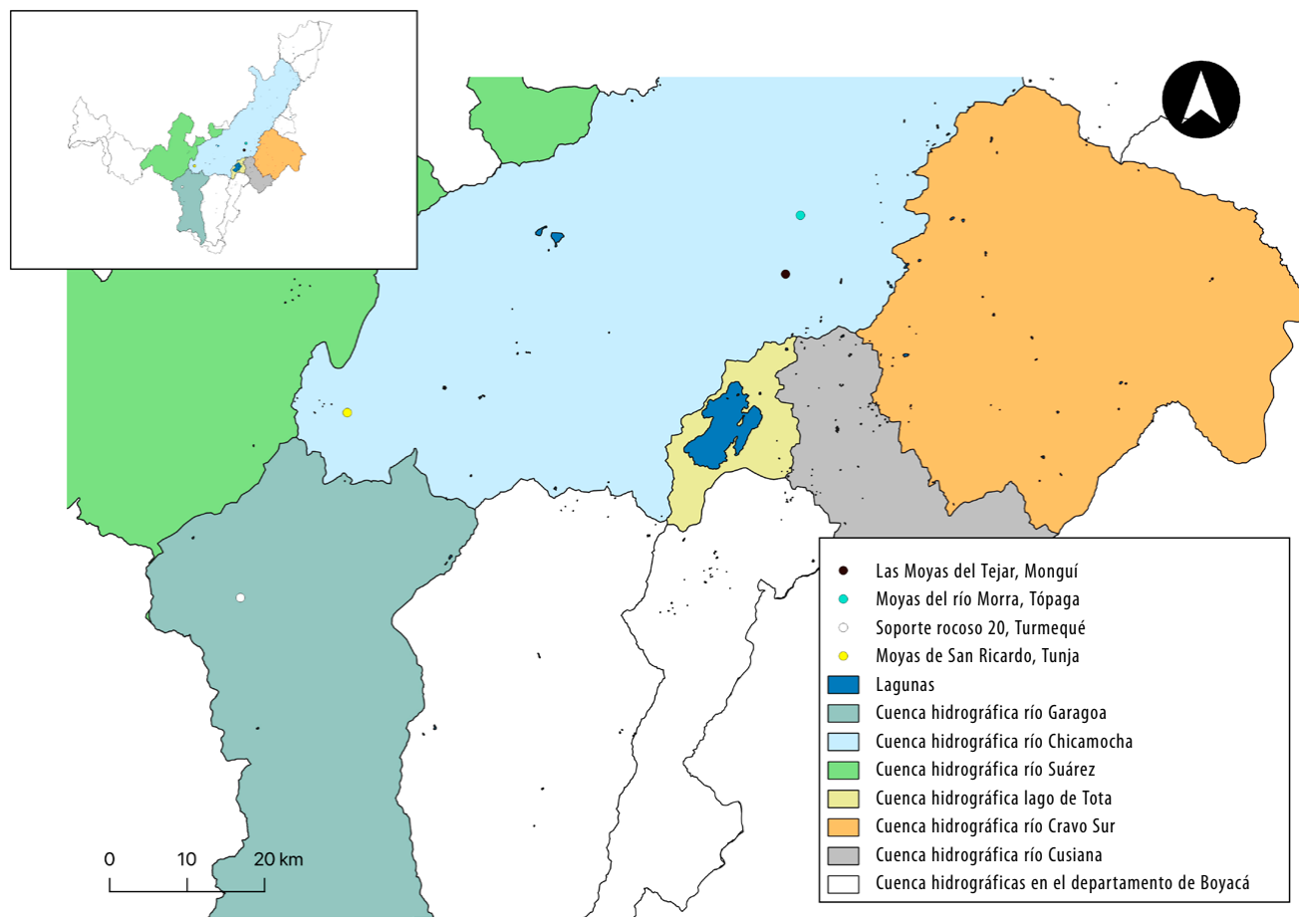

\section{Cuenca del río Chicamocha}

Veintiún municipios conforman la cuenca del río Chicamocha; en su mayoría coinciden con asentamientos prehispánicos documentados desde la etnohistoria. Arqueológicamente se ha registrado arte rupestre (Fundación Cultural 
Benítez 2016; López 2011; Pradilla 2001; Pradilla y Villate 2010), fragmentos de cerámica (Argüello 2016; Gutiérrez 1995; Pradilla et al. 1991), sitios funerarios (Pradilla 1989) y algunos cercados (Castillo 1984; Villate 2001) que corresponden a una ocupación continua por más de 2800 años, sin desconocer las dataciones de 8000 a. P. en el muncipio de Floresta. En cuanto a soportes rocososos con más de 8 cúpulas, encontramos la presencia de 3 soportes en la cuenca media y alta.

\section{Cuenca media}

A pocos metros de la confluencia de los ríos Morra y Chicamocha se localizan las Moyas del río Morra en el municipio de Tópaga. El soporte rocoso está ubicado en la parte más baja del valle, al margen oriental del río Morra y a pocos metros del antiguo camino a La Salina. Al realizar el análisis espacial en una distancia de $10 \mathrm{~km}$ lineales en sentido nororiental y suroriental entre el soporte y las lagunas, se evidenció una relación entre las 10 cúpulas cilíndricas de base plana y una oquedad alargada, con las 6 lagunas de la cuencas media del río Chicamocha y las 4 lagunas de la cuenca del río Cravo Sur (figura 5). Sin embargo, es necesario aclarar la existencia de la oquedad en el soporte rocoso, de mayor tamaño que las cúpulas, la cual se encuentra en el suroccidente de la roca y coincide con la ubicación espacial del lago de Tota.

La ubicación de las Moyas del río Morra no solo parece estar relacionada con las lagunas; también delimita un corredor de $10 \mathrm{~km}$ arqueológicamente rico en pictografías, petroglifos, cúpulas, contextos funerarios primarios en abrigos rocosos, contextos funerarios secundarios en cuevas de menor tamaño y sitios habitacionales con abundante cerámica de los periodos Herrera y Muisca. Lo anterior, en la parte alta del valle, en la ribera del río Sasa (López 2011), principalmente en los límites de los municipios de Gámeza, Mongua y Tópaga. Los dos soportes rocosos se sitúan a más de $20 \mathrm{~km}$ lineales del sitio arqueológico La Salina de Mongua, ubicado en la cuenca del río Cravo, lugar arqueológico documentado por Silva (1968) como un sitio único de estatuaria chibcha (Acero 2015).

A menos de $8 \mathrm{~km}$ lineales al sur de las Moyas del río Morra se encuentran las del Tejar, en el municipio de Monguí. El soporte rocoso cuenta con 11 cúpulas cóncavas cónicas profundas, 4 cúpulas cóncavas semiprofundas y 1 oquedad alargada, para un total de 16 moyas. Están ubicadas en la parte alta del valle, en el margen oriental de la quebrada que divide el sector con el poblado urbano de Monguí. Al realizar un análisis espacial del contexto lacustre del soporte rocoso, 
Figura 5. Moyas, lagunas y sitios arqueológicos de la cuenca media del río Chicamocha

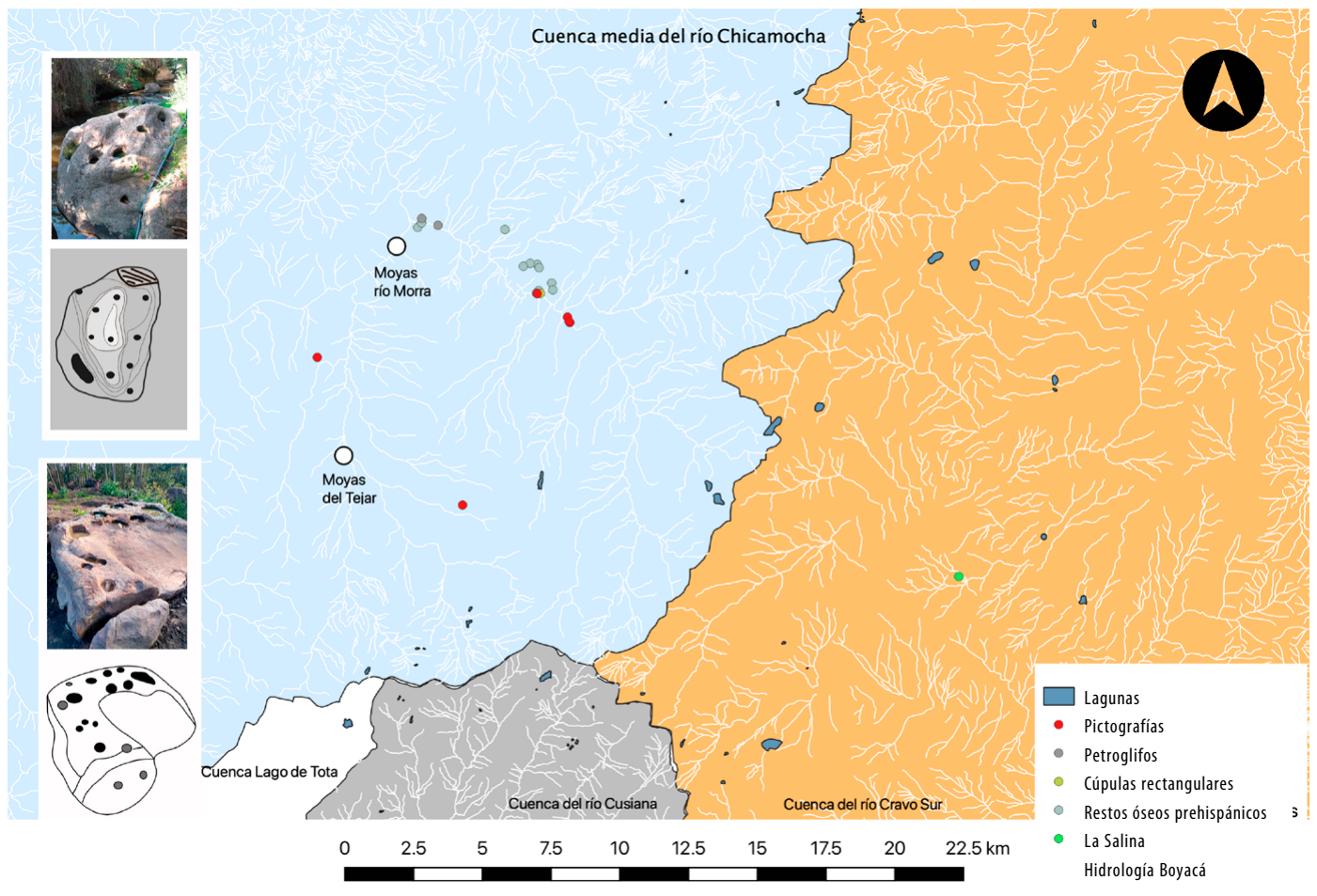

Fuente: elaboración propia.

se hallaron 25 lagunas en menos de $10 \mathrm{~km}$ lineales en sentido oriental y sur del soporte. Es de señalar la existencia de 9 lagunas en la cuenca media del río Chicamocha, 12 en la cuenca del río Cusiana, 3 en el norte de la cuenca del río Cravo sur y 1 en la cuenca del lago de Tota (figura 5).

Arqueológicamente se han documentado pictografías y aterrazamientos a menos de $8 \mathrm{~km}$ del soporte. Es particular el trabajo de percusión en la parte suroriental de la roca, de más de un metro, notoriamente distinto al de los demás soportes con cúpulas en el área estudiada, del cual se desconoce su posible uso y función. No obstante, pobladores de la zona reconocen el sitio como "el lugar donde iban a parir las indias", lo cual puede inducir a estudios futuros que confirmen o rechacen la hipótesis. 


\section{Cuenca alta}

El único soporte rocoso con más de 8 cúpulas en la cuenca alta del río Chicamocha documentado a la fecha corresponde a Las Moyas de San Ricardo, ubicadas a $500 \mathrm{~m}$ del Cercado Grande de los Santuarios, sitio funerario de la Hunza prehispánica, declarado área arqueológica protegida de Tunja. Allí se han recuperado más de 500 enterramientos pertenecientes a los periodos Muisca y Herrera (Acuña y Pradilla 2004; Castillo 1984; Gutiérrez 1995, 1998; Gutiérrez y Villate 1997; Hernández de Alba 1937a, 1937b; Museo Arqueológico de Tunja 1997; Pradilla 1989, 2007; Pradilla et al. 1999; Pradilla et al. 1991; UPTC 1993; UPTC y UNAL 2014; Villate y Gutiérrez 1997).

El soporte rocoso está a $3 \mathrm{~km}$ de un corredor de más de 200 soportes rocosos con pictografías en la ribera del Farfacá, lugar de preparación de sacerdotes y caciques muiscas (Pradilla, Villate y Ortiz 1992; Pradilla y Villate 2010; Villate 2001). El paisaje es referenciado por los cronistas como lugar de baño y limpieza de caciques y sacerdotes (Villate 2001). La distribución espacial evidencia tres sectores de cúpulas y oquedades en la ribera del Farfacá, lo que posibilita comprender la relación de las Moyas de San Ricardo con el corredor de pictografías, es decir, con el espacio de formación de sacerdotes y caciques (Villate 2001, 105). De ahí que exista un posible uso ritual de las cúpulas en el proceso de formación política y religiosa en épocas prehispánicas, de igual manera que funcionaban las lagunas.

Al realizar el análisis espacial del soporte y las lagunas del área circundante a Las Moyas de San Ricardo, encontramos que la piedra cuenta con 20 cúpulas cónicas cóncavas en total, 17 cúpulas profundas con un diámetro que oscila entre los 10 y $40 \mathrm{~cm}$ y 3 cúpulas semiprofundas con diámetros menores a los $8 \mathrm{~cm}$. Las 17 de profundidades y diámetros mayores a $10 \mathrm{~cm}$ coinciden con 9 lagunas de la cuenca alta en menos de $5 \mathrm{~km}$ lineales al occidente del soporte y 7 lagunas de la cuenca del río Suárez a $10 \mathrm{~km}$ lineales al noroccidente del soporte rocoso (figura 6). 
Figura 6. Las moyas de San Ricardo en relación con lagunas y sitios arqueológicos

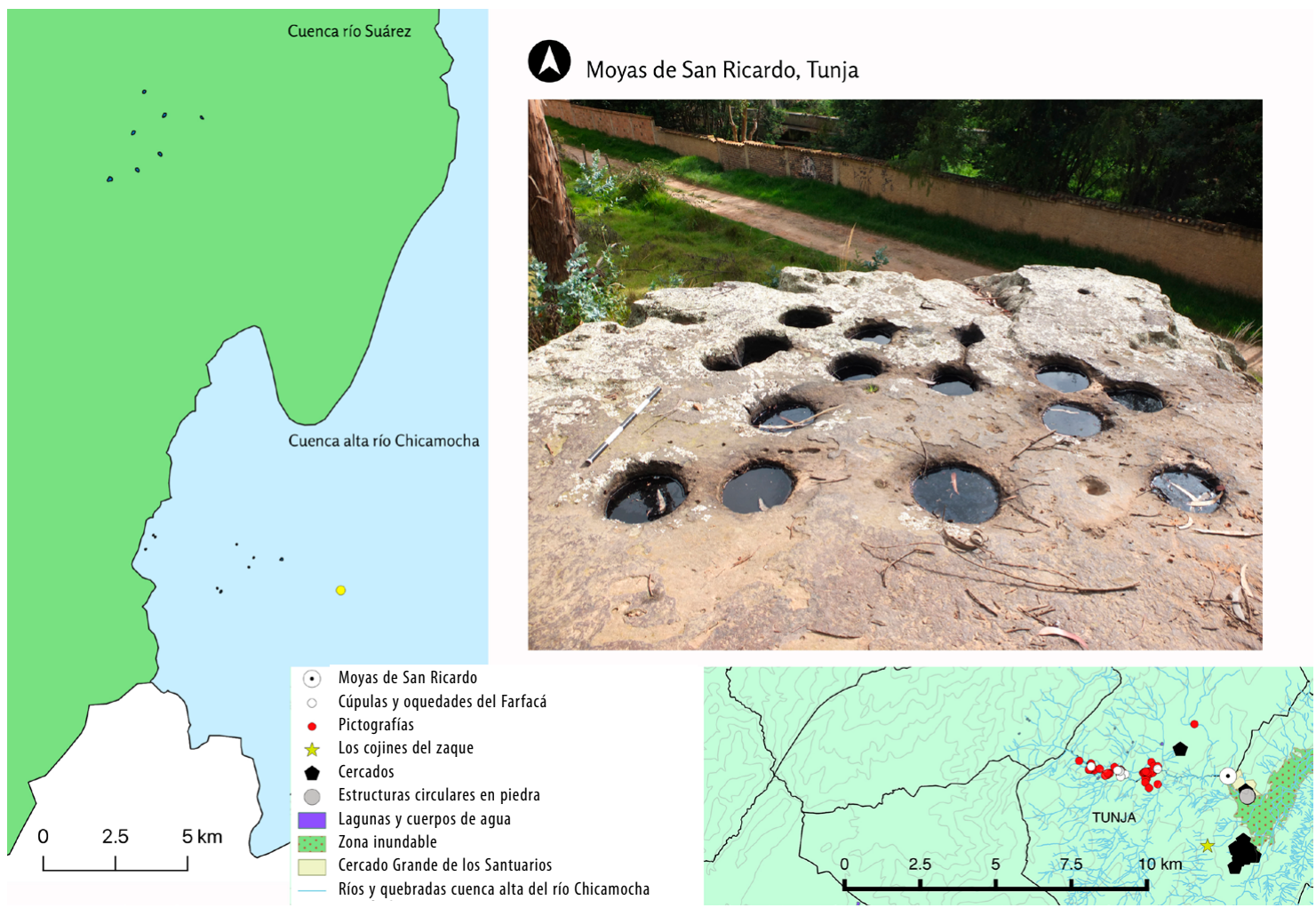

Fuente: elaboración propia

\section{Cuenca del río Garagoa}

Encontramos dos soportes rocosos con más de 8 cúpulas en la cuenca del río Garagoa, Las Moyas de Turmequé o soporte rocoso 20 del SAR La Magdalena y 9 pilas en el municipio de Úmbita. Para el análisis espacial hídrico y arqueológico, se recurrió a Las Moyas de Turmequé, una gran roca de forma piramidal que contiene 6 oquedades semiprofundas alargadas y 8 cúpulas cónicas profundas. El soporte hace parte del sitio con arte rupestre La Magdalena, donde hay nacimientos de agua, otras cúpulas y oquedades (Benavides 2020). A menos de 10 $\mathrm{km}$ existen otros lugares con arte rupestre, específicamente con pictografías y petroglifos, y algunos asentamientos prehispánicos descritos por la etnohistoria.

Espacialmente el soporte está estratégicamente ubicado. A simple vista parece alineado con el cerro que se encuentra detrás y, cuando se profundiza en el análisis espacial, pareciera marcar dos direcciones, al norte el páramo de 
Rabanal y al sur el páramo de Guacheneque. Al contrastar con la cartografía hídrica, encontramos que el soporte se localiza a menos de $30 \mathrm{~km}$ de la laguna de Fúquene y a menos de $10 \mathrm{~km}$ de varias lagunas de las cuencas de los ríos Garagoa, Chicamocha y Bogotá (figura 7).

Figura 7. Moyas y lagunas en la cuenca del río Garagoa

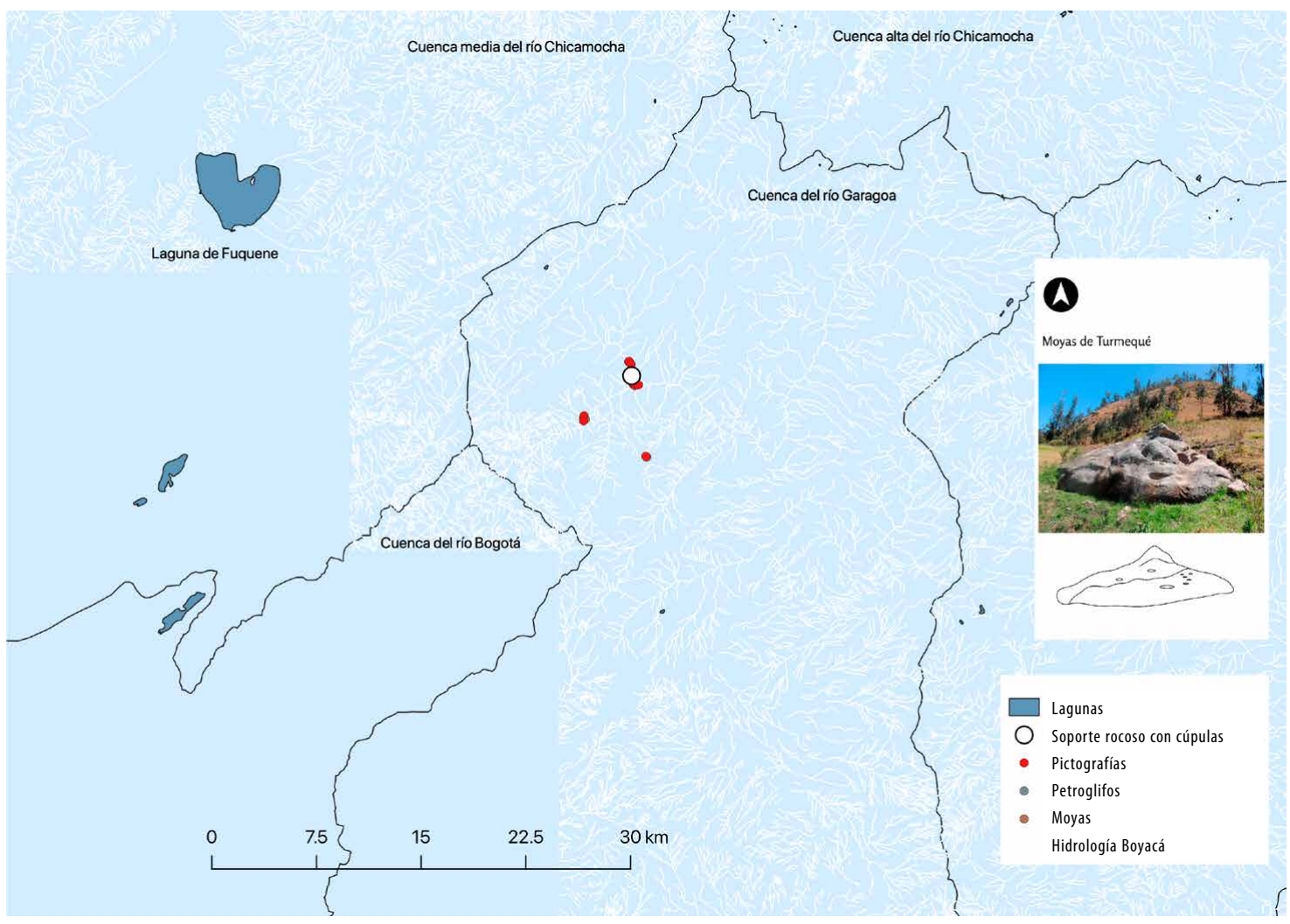

Fuente: elaboración propia.

\section{¿Los soportes rocosos con cúpulas son posibles maquetas hídricas en los Andes orientales?}

Aunque los cuerpos de agua y las lagunas pudieron haber aumentado o disminuido desde épocas prehispánicas hasta la actualidad, es pertinente reconocer las evidencias arqueológicas correspondientes a ofrendas votivas, fragmentos de 
cerámica muisca y documentos coloniales sobre la importancia mítica y religiosa de las lagunas del altiplano cundiboyacense, aún existentes en los ecosistemas de páramo. Ejemplo de ello es la laguna de Iguaque, referente mítico del origen muisca, de donde emergió la humanidad.

Durante los reconocimientos y prospecciones arqueológicas en los alrededores de las lagunas se han encontrado fragmentos cerámicos del periodo Muisca, lo cual confirma la importancia ritual y mítica de estos sitios como lugares de origen. No obstante, hacen falta excavaciones en área de los contextos de soportes rocosos con cúpulas que permitan correlacionar su temporalidad. Por ahora, reconocemos: a) una distancia de 10 a $30 \mathrm{~km}$ lineales entre las lagunas más cercanas y lejanas a los soportes rocosos con cúpulas; b) la diversidad de los soportes rocosos y técnicas de elaboración de cúpulas; c) la separación intencional de cúpulas en sectores dentro del mismo soporte rocoso; y d) la representación de cúpulas conectadas intencionalmente por canales naturales o antrópicos que coinciden con el número de ríos en el área.

Analizar las cúpulas desde una perspectiva espacial regional permite reconocer no solo el contexto arqueológico, sino el paisaje en el que se encuentran. Esto posibilita comprender las moyas de San Ricardo, Turmequé, El Tejar y el río Morra como posibles maquetas hídricas que representaban las lagunas y ríos principales de la región, lugares simbólicos y míticos en la cosmovisión muisca. De igual manera, encontramos algunas diferencias entre maquetas: las cúpulas de San Ricardo, Úmbita y El Tejar están en superficies planas del soporte rocoso, con pocos grados de inclinación, mientras las de Turmequé y el río Morra corresponden a soportes rocosos piramidales con superficie irregular.

Esta última característica no descarta la posibilidad de pensar en maquetas más complejas que representen las lagunas con probables variaciones en sus alturas, como se comprobó en el análisis altimétrico de las cúpulas del río Morra y las lagunas cercanas, donde se evidenció una relación con cinco alturas (3100, 3300, 3500, 3700 y 3800 ms.n.m.). Las lagunas más grandes del sur de la cuenca media del río Chicamocha, ubicadas hoy en los municipios de Gámeza, Monguí, Mongua y Tópaga, coinciden en número y altura con las cúpulas talladas en la roca del río Morra. Una laguna está a 3100 ms.n.m., dos están a 3300 ms.n.m.; dos, a 3500 m s. n. m.; una, a 3600 m s. n. m.; tres, a 3700 ms.n.m.; y una, a 3800 m s. n. m. La única oquedad de la roca, situada en la parte baja, coincide con la altura y ubicación espacial del lago de Tota, conocido como el segundo cuerpo de agua más grande y alto de Suramérica. De ser así, las moyas del río Morra no representarían los cuerpos de agua del sur de la cuenca del río Chicamocha, sino once de los cuerpos de agua más grandes, posiblemente reconocidos mitológica y ritualmente en épocas prehispánicas. 


\section{Consideraciones finales}

Abordar las cúpulas como elementos constitutivos del arte rupestre permite ampliar el campo arqueológico, no solo para cuantificar y describir las características propias de las cúpulas y sus técnicas de elaboración, sino para comprender la configuración paisajística, los contextos prehispánicos y las múltiples relaciones que las comunidades han establecido con el ambiente. El estudio de las cúpulas se hace pertinente en la comprensión de sitios con arte rupestre (SAR), definidos por Martínez (2015) como "la extensión de terreno (superficial y subterráneo) que contiene o está relacionado con el emplazamiento rocoso en que se inscriben los motivos rupestres - pintados o grabados - constitutivos del patrimonio arqueológico" (169). Para el caso específico de las cúpulas, se hace necesaria una visión más amplia del entorno, que no refiera al más próximo, sino que vincule el paisajístico, es decir, el configurado por las poblaciones prehispánicas, tal y como se relacionan las comunidades indígenas en la actualidad.

La lectura amplia del entorno en los SAR favorece la comprensión de las cúpulas más allá que como contenedores, recipientes y espejos estelares. Si bien López (2011) reconocía el uso astronómico de las moyas del río Morra, parece no ser la única hipótesis en el uso y función de los soportes rocosos con varias cúpulas. Si observamos la distribución de las cúpulas en las moyas de San Ricardo, el río Morra y Turmequé, encontramos coincidencias entre el número de cúpulas y el número de lagunas de la parte alta, entre 8 y $30 \mathrm{~km}$ lineales. Esta coincidencia permite comprenderlas como posibles maquetas hídricas ubicadas en la parte baja de las cuencas de los ríos en los Andes orientales colombianos. La hipótesis anima a continuar en el análisis de la distribución espacial de las rocas con varias cúpulas, como las registradas en Mongua, Socha, Úmbita, Suba y Cota, territorio reconocido arqueológicamente como muisca.

Si bien el hecho de pensar y delimitar las áreas por cuencas parece responder a los conceptos y relaciones modernas de la geografía, los trabajos etnográficos y etnoarqueológicos realizados en el área nos han ayudado a comprender las otras relaciones entre la gente y el agua. Los campesinos del altiplano cundiboyacense (Carrillo 1997; López 2011; Monsalve 2004; Rozo 1997, 2006) y los indígenas del Cauca (Escobar 2019; Dagua, Aranda y Vasco 1998; Faust 2004; Pachón 1996; Portela 2000; Restrepo 2011) siempre han reconocido los caminos del agua como propios, tanto así que en los relatos míticos y de ordenamiento territorial aparecen las lagunas y ríos como ejes centrales para el desarrollo de la vida.

De las lagunas salieron los dioses y caciques, los seres originarios de estos mundos que bajaron por los ríos y fundaron los pueblos. Luego de un tiempo 
regresaron a las lagunas y, por cientos de años, se les va a orar, se les llevan ofrendas y se marcan con cruces las piedras que están a su alrededor. El posible uso de cúpulas como referentes paisajísticos en épocas prehispánicas amplía el campo investigativo en relación con los tamaños de diámetros y profundidades de las cúpulas. Aunque las moyas de Mongua, San Ricardo, Úmbita, Socha y Motavita se elaboraron sobre un soporte uniforme plano, las de Tópaga, Turmequé y Gámeza difieren en su distribución sobre el soporte.

Los soportes rocosos analizados muestran inclinaciones y alturas elegidas para la realización de las cúpulas, como si estuviesen representando las alturas de las montañas y valles en donde se encuentran las lagunas. Además, es importante resaltar una diferencia en la técnica de elaboración entre las moyas, pues encontramos cúpulas cónicas cóncavas y cúpulas cilíndricas de base plana y redondeada, lo que genera múltiples interrogantes: ¿fueron los mismos grupos humanos los realizadores de las cúpulas?, ¿tendrían usos y funciones distintas?, ¿serán estas rocas la representación de mapas que, desde la oralidad, reconocen los pobladores de la región?

Responder estas preguntas es la motivación de un camino investigativo que recién comienza. Las cúpulas parecen brindar más información arqueológica de la esperada; su aparición en los SAR da la posibilidad de entenderlas como parte de los mensajes que quisieron ser comunicados desde épocas prehispánicas y cuya comprensión se hace difícil en contextos campesinos, como el del altiplano cundiboyacense. De ahí la importancia de continuar el registro sistemático en los estudios arqueológicos, de vincularlas como elemento constitutivo del arte rupestre, y de avanzar en los análisis espaciales que dan luces para la comprensión de las relaciones sociales y culturales que las poblaciones establecieron con las cúpulas.

Definir usos y funciones de las cúpulas en épocas prehispánicas es arriesgado; sin embargo, los trabajos etnográficos permiten entenderlas como parte de la cotidianidad boyacense. La gente se refiere a ellas con el término de moyas porque las consideran como contenedores, como recipientes u ollas que posibilitan el almacenamiento y hervido de bebidas, así como la cocción de comidas. Para confirmar su uso en épocas prehispánicas es necesaria la excavación en área de las rocas con cúpulas, para identificar rocas de menor tamaño con huellas de termofractura y elementos asociados a procesos de combustión.

Sus elementos minerales posiblemente acompañaron los partos en Iza y Monguí. Mediante la ingestión del líquido que se contenía en las cúpulas, alivianaron las cargas y dominaron el sueño de niños inquietos en Gámeza (López 2011). Ante las prácticas medicinales tradicionales descritas, López (2019) 
manifiesta la importancia de realizar estudios arqueométricos que permitan descubrir las propiedades físicas y químicas de las aguas que reposan en las cúpulas y que son consumidas con fines de curación. Tal investigación interdisciplinar aportaría a los campos de la medicina, la física, la química y la arqueología, lo que amplía el conocimiento sobre los modos de supervivencia en sociedades prehispánicas.

\section{Referencias}

Acero Díaz, Dally Viviana. 2015. "Análisis y reconocimiento histórico-espacial de la Salina de Mongua”. Pensamiento y Acción 20: 34-44. https://revistas.uptc.edu.co/index.php/pensamiento_accion/article/view/4013

Acuña, Blanca y Helena Pradilla. 2004. "Inventario y registro de monolitos de la UPTC". Informe de Avance UPTC Tunja, Dirección de Investigaciones y Museo Arqueológico de Tunja. https://www.academia.edu/36156830/Inventario_y_registro_de_monolitos_UPTC

Argüello, Pedro. 2016. “Cacicazgos prehispánicos en Tunja. Estudio de los patrones de asentamiento en Motavita-Boyacá”. Informe de investigación. ICANH, Bogotá.

Aschero, Carlos. 2007. "Iconos, huancas y complejidad en la puna sur argentina”. En Producción y circulación prehispánicas de bienes en el sur andino, editado por Axel Nielsen, 135-166. Córdoba: Brujas.

Bednarik, Robert. 2008. “Cupules”. Rock Art Research 25: 61-100. https://www.researchgate. net/publication/281317650_Cupules

Benavides, Jaime. 2020. "Reconocimiento del patrimonio arqueológico del municipio de Turmequé, Boyacá. Primera medida para su gestión y apropiación”. Trabajo de grado, Facultad de Ciencias de la Educación, Universidad Pedagógica y Tecnológica de Colombia, Tunja.

Botiva, Álvaro y Diego Martínez. 2004. Manual de arte rupestre de Cundinamarca. Gobernación de Cundinamarca. Bogotá: ICANH.

Carrillo, María. 1997. “Los caminos del agua. Según la tradición oral de los raizales de la sábana de Bogotá". Trabajo de grado, Departamento de Antropología, Universidad Nacional de Colombia, Bogotá. http://www.luguiva.net/invitados/detalle.aspx?id=29

Carrión, Rebeca. 2005. El culto al agua en el antiguo Perú. Lima: Instituto Nacional de Cultura.

Castillo, Neila. 1984. Arqueología de Tunja. Bogotá: FIAN.

Correa, François. 2004. El sol del poder. Simbología y política entre los muiscas del norte de los Andes. Bogotá: Universidad Nacional de Colombia. 
Dagua, Abelino, Misael Aranda y Luis Vasco. 1998. Guambianos. Hijos del aroirisy del agua. Bogotá: Cerec; Los Cuatro Elementos; Fundación Ángel Escobar; Fondo Promoción de la Cultura Banco Popular.

Escobar, Luis. 2019. “Aportes al Proyecto Educativo Comunitario, PEC. Un diálogo entre la ciencia y el saber indígena”. En Memorias, conocimientos y cambios en diseño y construcción de la nasa yat, Cauca, Colombia, editado por Jairo Tocancipa Falla, 113-129. Popayán: Universidad del Cauca.

Fajardo, Sebastián. 2016. "Prehispanic and Colonial Settlement Patterns of the Sogamoso Valley”. Tesis doctoral, Department of Anthropology, University of Pittsburgh, Pittsburgh. http://d-scholarship.pitt.edu/29329/1/fajardoETD2016.pdf

Faust, Franz. 2004. Un viaje por paisajes míticos de Colombia. Popayán: Universidad del Cauca.

Flórez Páez, Ana Lucía. 2008. "Del pensamiento a la piedra y de la piedra al pensamiento. Piedras con dibujos en el Valle del Sibundoy”. Tesis de pregrado, Departamento de Antropología, Universidad de Antioquía, Medellín.

Fundación Cultural Benítez. 2016. Senderos rupestrológicos en tierras del cacique Socha. Tunja: Buhos Editores.

Fundación Desierto de Atacama. 2016. "Arte rupestre: técnicas, estilos y primeras evidencias”. Consultado el 20 de septiembre de 2021. https://www.fundaciondesiertoatacama.cl/ noticias/arte-rupestre-tecnicas-estilos-y-primeras-evidencias/

Guffroy, Jean. 1999. El arte rupestre del antiguo Perú. Lima: Instituto Fránces de Estudios Andinos.

-. 2011. "Las tradiciones centro-andinas de rocas grabadas (Perú): evoluciones y continuidades”. Chungara, Revista de Antropología Chilena 43: 73-88. http://dx.doi.org/10.4067/S071773562011000100005

Gutiérrez, David, José González y Ramón Artiles. 2014. “¿Cúpulas en Cuba? Primera aproximación a la posible presencia de petroglifos cupulares en la mayor de las Antillas”. En Arqueología precolombina en Cuba y Argentina: esbozos desde la periferia, editado por Ana Rocchietti y Odlanyer Hernández de Lara, 117-144. Buenos Aires: Aspha.

Gutiérrez, Jaime. 1995. "Prospección arqueológica de la Universidad Pedagógica y Tecnológica de Colombia. Área de la Bomba”. UPTC, Tunja.

—. 1998. "Informe. Estudio de reconocimiento y prospección arqueológica sitio Laboratorios 'El Corazón”. UPTC., Tunja.

Gutiérrez, Jaime y Germán Villate. 1997. "Proyecto de Arqueología del Bosque Sector Sur, fase I". Informe de avance presentado a Instituto de Investigaciones y Formación Avanzada (IIFA). UPTC, Tunja. https://www.academia.edu/36156546/Proyecto_de_arqueolog\%C3\%ADa_del_Bosque_Sector_sur_Fase_II_Informe_de_avance

Hernandez de Alba, Gregorio. 1937a. “Arqueología del templo de Goranchacha”. Revista de las Indias 37: 10-18.

Hernandez de Alba, Gregorio. 1937b. El mito de Goranchachay las excavaciones en la Normal de Tunja. Tunja: Ministerio de Educacion y Bellas Artes. 
Langebaek, Carl. 2019. Los muiscas. La historia milenaria de un pueblo chibcha. Bogotá: Penguin Random House.

León, Clara, Daniel Barón y Mónica Giedelmann. 2018. "Caracterización de soportes de estaciones rupestres en el cañón del Chicamocha”. En Arte rupestre en Colombia. Investigación, preservación, patrimonialización, editado por Pedro Argüello, 109-126. Tunja: UPTC.

Lleras Pérez, Roberto. 1986. “Arqueología del Alto Valle de Tenza”. Boletín de Arqueología 1: 31-24. https://publicaciones.banrepcultural.org/index.php/fian/article/view/6082

López Estupiñán, Laura. 2011. “Topando piedras sumercé. Narraciones en torno a las piedras de Iza y Gámeza, Boyacá, Colombia”. Tesis de pregrado, Departamento de Antropología y Sociología, Universidad del Cauca, Popayán.

-. 2019. "Arte rupestre y prácticas culturales de gentes andinas”. Cuadernos de Arte Prehistórico 7: 196-210. https://www.cuadernosdearteprehistorico.com/index.php/cdap/article/ view/63

Marchante, Ángel. 2016. "Análisis macro y microespacial del abrigo inédito de Puerto Baterno (Aguso, Ciudad Real) y su inserción dentro del arte rupestre esquemático de los Montes de Ciudad Real, Valle de Alcudia y Sierra Madrona”. Vínculos de Historia 5: 161-195. http:// dx.doi.org/10.18239/vdh.v0i5.011

Martínez, Diego. 2015. Lineamientos para la gestión patrimonial de sitios con arte rupestre en Colombia como insumo para su apropiación social. Bogotá: Ministerio de Cultura de Colombia.

Menghin, Oswaldo. 1958. "Las piedras de cúpula con referencia especial a la Argentina”. Separata de la Revista de Educación de la Provincia de Buenos Aires 6: 422-438.

Methfessel, Carlos y Lilo Methfessel. 1998. "Cúpulas en rocas de Tarija y regiones vecinas. Primera aproximación”. Boletín SIARB 12: 36-47. https:/dokumen.tips/documents/ methfessel-c-y-l-methfessel-1998-cupulas-en-rocas-de-tarija-y-regiones.html

Milla, Carlos. 2006. Génesis de la cultura andina. Lima: Asociación de Investigación y Comunicación Cultural Amaru Wayra.

Monsalve, Dora. 2004. La humanidad de las semillas sembradas en la santa tierra: la economía campesina en el Valle de Tenza. Bogotá: UNAL.

Municipio de Soacha, Idecut (Instituto Departamental de Cultura y Turismo de Cundinamarca) y Fundación Erigaie. S.f. "Soacha Rupestre. Inventario de Sitios con Arte Rupestre (SAR) del municipio de Soacha”.

Muñoz Castiblanco, Guillermo. 2006. Patrimonio rupestre. Historia y hallazgos. Bogotá: Alcaldía El Colegio; Gipri.

Museo Arqueológico de Tunja. 1997. “Informe Proyecto en Red”. UPTC, Tunja.

Ortiz, Francisco y Helena Pradilla. 2000. Rocas y petroglifos del Guainía. Tunja: Fundación Etnollano; Museo Arqueológico de Tunja; UPTC.

Pachón Castrillón, Jimena. 1996. “Los nasa o gente paez”. En Geografía humana de Colombia. Región Andina Central, vol. 4, 61-106. Bogotá: Instituto Colombiano de Cultura Hispánica. 
Ponzio, Arabela. 2018. "Rocas con cúpulas en el sur de la sierra de Comechingones. Una revisión bibliográfica”. Revista Sociedades de Paisajes Áridos y Semi-áridos 16: 78-95. http:// www2.hum.unrc.edu.ar/ojs/index.php/spas/article/view/693

Portela, Hugo. 2000. El pensamiento de las aguas de las montañas. Coconucos, guambianos, paeces, yanaconas. Popayán: Universidad del Cauca.

Pradilla, Helena. 1989. Estudio de enterramientos humanos en el altiplano cundiboyacense. Tunja: UPTC.

—. 2001. "Farfacá. Patrimonio cultural y natural de Tunja y Motavita. Inventario, registro y preservación de pictografías y moyas del río Farfacá”. Grupo de Investigaciones Arqueológicas e Históricas de la UPTC, Tunja.

—. 2007. "Rescate arqueológico zanja eléctrica UPTC”. Informe del proyecto n. ${ }^{\circ}$ SGI 484 . Grupo de Investigaciones Arqueológicas e Históricas; UPTC; Museo Arqueológico de Tunja. UPTC, Tunja.

Pradilla, Helena y Germán Villate. 2010. Pictografías, moyas y rocas del Farfacá. Tunja: UPTC.

Pradilla, Helena, Germán Villate, Blanca Acuña y Helena Castaño. 1999. Arqueología y restauración. La cerámica. Tunja: UPTC.

Pradilla, Helena, Germán Villate y Francisco Ortiz. 1992. "Arqueología del Cercado Grande de los Santuarios”. Boletín Museo del Oro 32-33: 21-147. https://publicaciones.banrepcultural.org/index.php/bmo/article/view/7011

Pradilla, Helena, Germán Villate, Luis Wiesner y Francisco Ortiz. 1991. Estudio arqueológico de la UPTC. Tunja: UPTC; Instituto Colombiano de Cultura.

Querejazu, Roy. 1998. “Tradiciones de cúpulas en el departamento de Cochabamba”. Boletín SIARB 12: 48-58. http://siarb-bolivia.org/wp-content/uploads/2019/08/bol12d.pdf

Restrepo, Roberto. 2011. "Visión andina del agua”. En Agua: un patrimonio que circula de mano en mano, 77-93. Bogotá: Banco de la República.

Rivas, Pilar y Carlos Ocampo. 2005. "El antiguo curanto chilote”. En Chile país oceánico, editado por Gonzalo Badal Mella, 70-72. Santiago de Chile: Ocho Libros Editores.

Rodríguez, José. 2015. El Parque Arqueológico de Facatativá: proceso de recuperación y conservación de la memoria de sus antiguos habitantes. Bogotá: CAR; UNAL.

Rozo, José. 1997. Mito y rito entre los muiscas. Bogotá: El Búho.

—. 2006. "Bachué: Relación mito-arte rupestre”. Consultado el 20 agosto de 2019. www.rupestreweb.info/bachue.html

Schobinger, Juan. 1969. Prehistoria de Suramérica. Barcelona: Labor.

Silva, Eliécer. 1968. "Las estatuas de la Salina de Mongua”. En Libro Azul, editado por Honorio Cortés, 147-162. Tunja: UPTC.

Simón, fray Pedro. 1981. Noticias historiales de las conquistas de tierra firme en las Indias Occidentales. Vol. II. Bogotá: Biblioteca Banco Popular. 
Troncoso, Andrés. 1998. "Petroglifos, agua y visibilidad: el arte rupestre y la apropiación del espacio en el curso superior del río Putaendo, Chile”. Valles, Revista de Estudios Regionales 4: 127-137. http://repositorio.uchile.cl/handle/2250/122001

UPTC (Universidad Pedagógica y Tecnológica de Colombia). 1993. Patrimonio arqueológico: hacia una política de manejo. [Cartilla divulgativa]. Tunja: UPTC.

UPTC y UNAL (Universidad Pedagógica y Tecnológica de Colombia y Universidad Nacional de Colombia). 2014. "Cuadernos del Plan de Manejo Arqueológico de la UPTC. Documento de divulgación”. Contrato n. ${ }^{\circ} 333$ de 2012 UPTC/UN. Reformulación del Plan de manejo arqueológico de los parques museo de la Universidad Pedagógica y Tecnológica de Colombia (UPTC), Sede Central Tunja, Sogamoso, Villa de Leyva. UPTC; UNAL, Tunja.

Villate, Germán. 2001. Tunja prehispánica. Tunja: UPTC.

Villate, Germán y Jaime Gutiérrez. 1997. "Proyecto Arqueología del Bosque Sector Sur fase II. Estudio arqueológico y etnográfico de las cuadrículas 'L83 A L93”. Informe final. IIFA; UPTC, Tunja. 